ABDI: Jurnal Pengabdian dan Pemberdayaan Masyarakat

ISSN: 2656-369X (Print), 2684-8570 (Online)

Volume 3 No. 2, Desember 2021

http://abdi.ppj.unp.ac.id/index.php/abdi

Email: abdi@ppj.unp.ac.id

DOI: https://doi.org/10.24036/abdi.v3i2.88

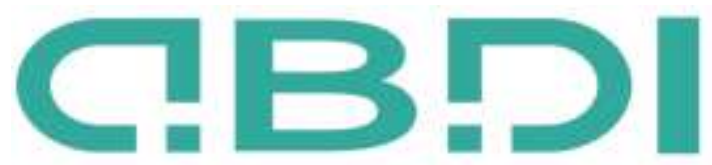

ABDE JURNAL PENGABDIAN DAN PEMBERDAYAN MUSYARAKAT

\title{
Rancang Bangun Mesin Pemarut Singkong untuk UKM Opak Singkong di Kecamatan Pangururan Kabupaten Samosir
}

\author{
Janter Pangaduan Simanjuntak ${ }^{1}$, Dina Sarah Syahreza ${ }^{2}$, Harun Sitompul ${ }^{3}$, Bisrul Hapis Tambunan ${ }^{4}$ \\ 1,2,3,4 Jurusan Pendidikan Teknik Mesin, Universitas Negeri Medan \\ E-mail: bisrulhapis@unimed.ac.id
}

\begin{abstract}
Abstrak
Dari hasil diskusi dengan Mitra telah disepakai bahwa permasalahan utama yang sangat mendesak untuk diselesaikan sehingga menjadi prioritas utama mereka adalah tentang Proses pemarutan Singkong yang masih menggunakan Pemarut Kelapa yang sangat membahayakan pekrja (Mitra)dan juga tidak efisien, karena harus menyisakan sekitar $3 \mathrm{~cm}$ singkong untuk pegangan. Oleh karena itu kedua mitra sangat berharap adanya bantuan mesin Pemarut Ubi (singkong). Tujuan dari Program ini adalah untu menyelesaikan permasalahan mitra dibidang produksi yakni pemarutan singkong. Tim dan Mitra menyepakati solusi mengadakan Mesin Pemarut singkong. Hal ini diharapkan dapat mempermudah proses pemarutan dan menjaga keselamatan operator pemarut serta mencegah adanya sisa singkong yang tidak dapat diparut pada parutan kelapa. Dari hasil pelaksanaan mitra merasa sangat puas deengan mesin pemarut hasil rancangan tim dan terbukti dapat mencegah adanya sisa singkong yang tidak dapat di parut dengan parutan kelapa, menguragi waktu produksi dan mencegak kecelakaan kerja.
\end{abstract}

Kata kunci: Opak, Pemarut, Singkong.

\section{Abstract}

From the results of discussions with partners, it has been agreed that the main problem that is very urgent to be resolved so that it becomes their top priority is the grating process of cassava which still uses a coconut grater which is very dangerous for workers (partners) and also inefficient, because they have to leave about $3 \mathrm{~cm}$ of cassava for processing. handle. Therefore, the two partners really hope for the assistance of a sweet potato (cassava) grater machine. The purpose of this program is to solve the problems of partners in the field of production, namely grating cassava. The team and partners agreed on a solution to provide a cassava grater machine. This is expected to facilitate the grating process and maintain the safety of the grater operator and prevent the remaining cassava that cannot be grated on the coconut grater. From the results of the implementation, partners are very satisfied with the grating machine designed by the team and it is proven to be able to prevent cassava residue that cannot be grated with a coconut grater, reduce production time and prevent work accidents.

Keyword: Cassava, Grate, Opak.

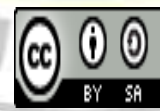




\section{Pendahuluan}

Opak singkong adalah jenis kerupuk dari olahan kerupuk yang berbahan dasar ketela yang dikukus terlebih dahulu. Setelah proses pengukusan, kerupuk yang dalam keadaan basah akan dijemur. (Deyulmar, Suroto, \& Wahyuni, 2018) Bedanya Opak singkong dengan keripik singkong adalah: Pembuatan Opak singkong melalui beberapa tahap yakni singkong di parut terlebih dahulu kemudian hasil parutan dipipihkan setipis mungkin, kemudian di kukus, di jemur lalu digoreng.(Ummi, Irman, Ferdinant, \& Gunawan, 2018) Sedangkan Keripik singkong hanya di iris (tidak diparut) lalau di goreng tanpa harus di kukus terlebih dahulu.(Rijanto \& Rahayuningsih, 2018).

Wilayah Kecamatan Pangururan merupakan salah satu wilayah Kabupaten Samosir yang dekat dengan pinggiran Kota Pangururan. Sebahagian besar penduduk di Kecamatan Pangururan adalah memiliki usaha sendiri, seperti opak singkoang, usaha keripik singkong, ternak ikan air tawar, dan bertani. (BPS Samosir, 2018)

Dari Hasil observasi dan diskusi dalam kunjungan yang dilakukan Tim ke Usaha Opak singkong kedua Mitra yakni Ibu Nantogi Sinaga yang bertempat Kelurahan Pasar, Kecamatan Pangururan, Kabupaten Samosir. Mitra memulai usaha ini sejak tahun 2007. Mitra mengelola usaha Opak ini bersama keluarganya yaitu suami dan tiga orang anaknya. Mitra 1 membutuhkan $30 \mathrm{Kg}$ Singkong per harinya. Singkong dibeli dari pasar dengan harga Rp. 50.000,-/goni ( setara dengan $20 \mathrm{~kg}$ ).
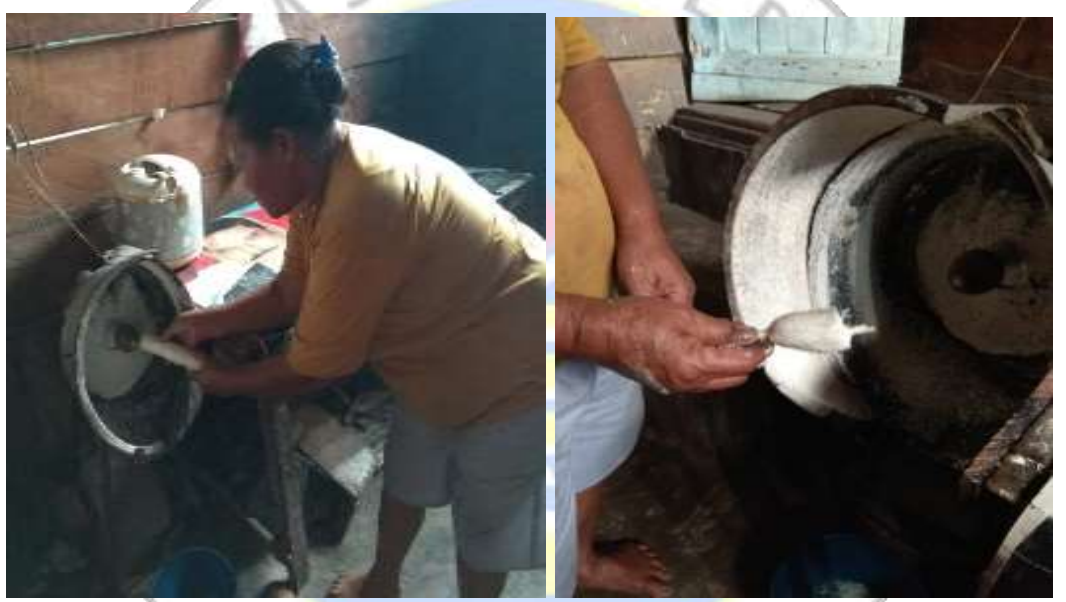

Gambar 1. Pemarutan menggunakan parutan kelapa

Proses pembuatan opak singkong terdapat beberapa tahapan yaitu Pengupasan Singkong, Penghalusan dengan cara di parut atau ditumbuk, Pemipihan, pengkukusan, Pengeringan atau penjemuran lalu penggorengan. Proses pembuatan opak singkong tersebut membutuhkan waktu yang lama terutama pada proses penghalusan dan pengeringan.(Rahmadani et al., 2019).

Pada proses penghalusan, Mitra masih menggunakan parutan kelapa, dimana parutan ini tidak dirancang untuk singkong sehingga sangat membahayakan bagi Mitra. Penggunaan peralatan yang tidak sesuai peruntukannya merupakan salah satu penyebab kecelakaan. (www.SafetySign.co.id, 2016). Menurut mitra sudah beberapa kali terjadi kecelakaan kerja yang mengakibatkan tangan Mitra terluka karena terkena parutan, hinga Mitra harus mendapatkan perawatan dan tidak dapat melakukan produksi selama beberapa hari. Hal ini menyebabkan tidak adanya pemasukan Mitra selama dalam perawatan. Penggunaan parutan kelapa juga membuat singkong tidak bisa terparut seluruhnya, selalu ada sisa sekitar $3 \mathrm{~cm}$ agar tangan tidak terkena parutan. 


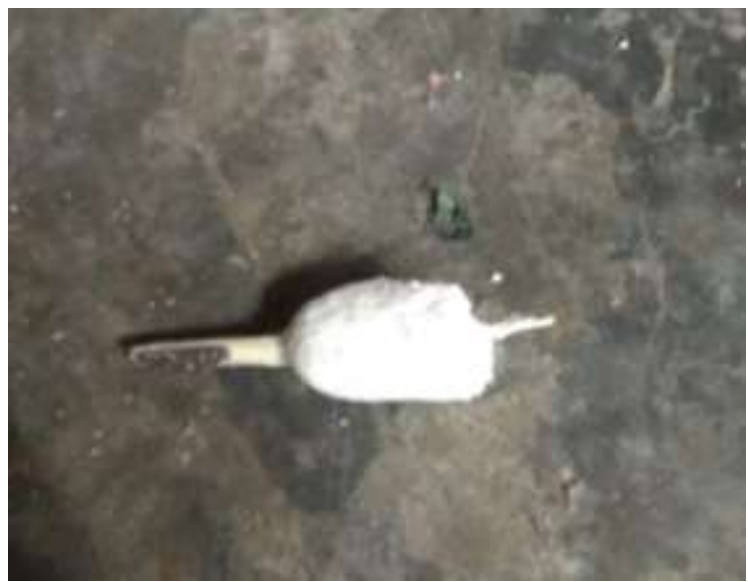

\section{Gambar 2. Sisa singkong yang tidak bisa di parut dengan parutan kelapa.}

\section{Metode}

Pada program PKM ini, model pemecahan solusi menggunakan diskusi, penerapan teknologi tepat guna dan pendampingan.

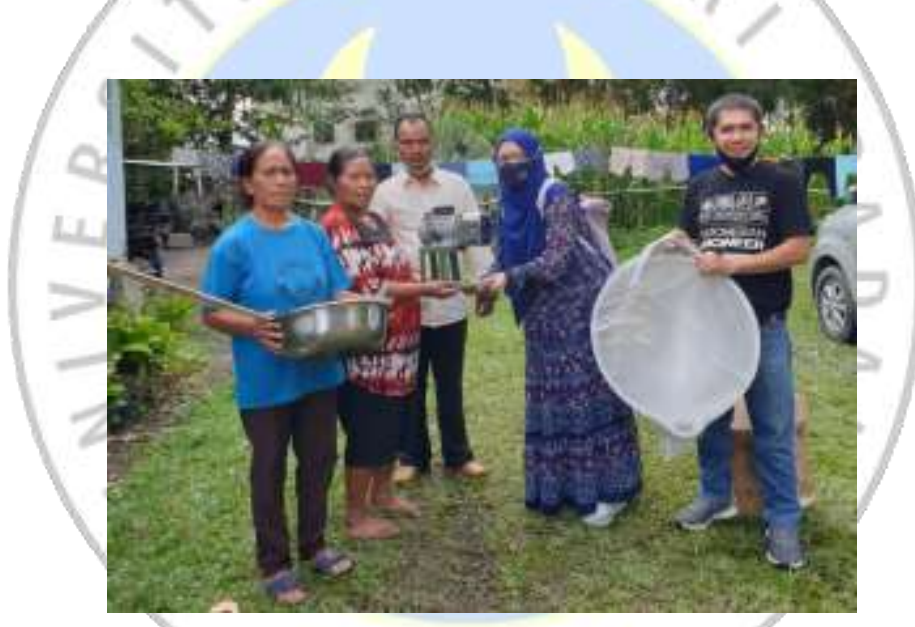

\section{Gambar 3. Penyerahan bantuan Mesin Pemarut dan perlengkapan lainnya}

\subsection{Diskusi}

Tim pelaksana program dari Universitas Negeri Medan dan mitra menggunakan metode diskusi sebagai sarana penetuan permasalahan utama dialami oleh mitra. Hal ini dilakukan agar mendapatkan solusi terbaik bagi mitra sehingga hasil dari pelaksanaan program PKM benar-benar mampu menyelesaikan permasalahan utama yang dihadapi mitra. Karena Pengambilan keputusan secara sepihak (subyektif) sangat rentan akan kesalahan.(Mude, 2016),(Muktiadji \& Hendrian, 2018) Diskusi diikuti oleh Ibu Nantogi sinaga sebagai Pemilik usaha dan dan 2 orang anaknya yang juga sebagai karyawan dalam UKM ini dengan 3 orang tim pelaksana dari UNIMED. 

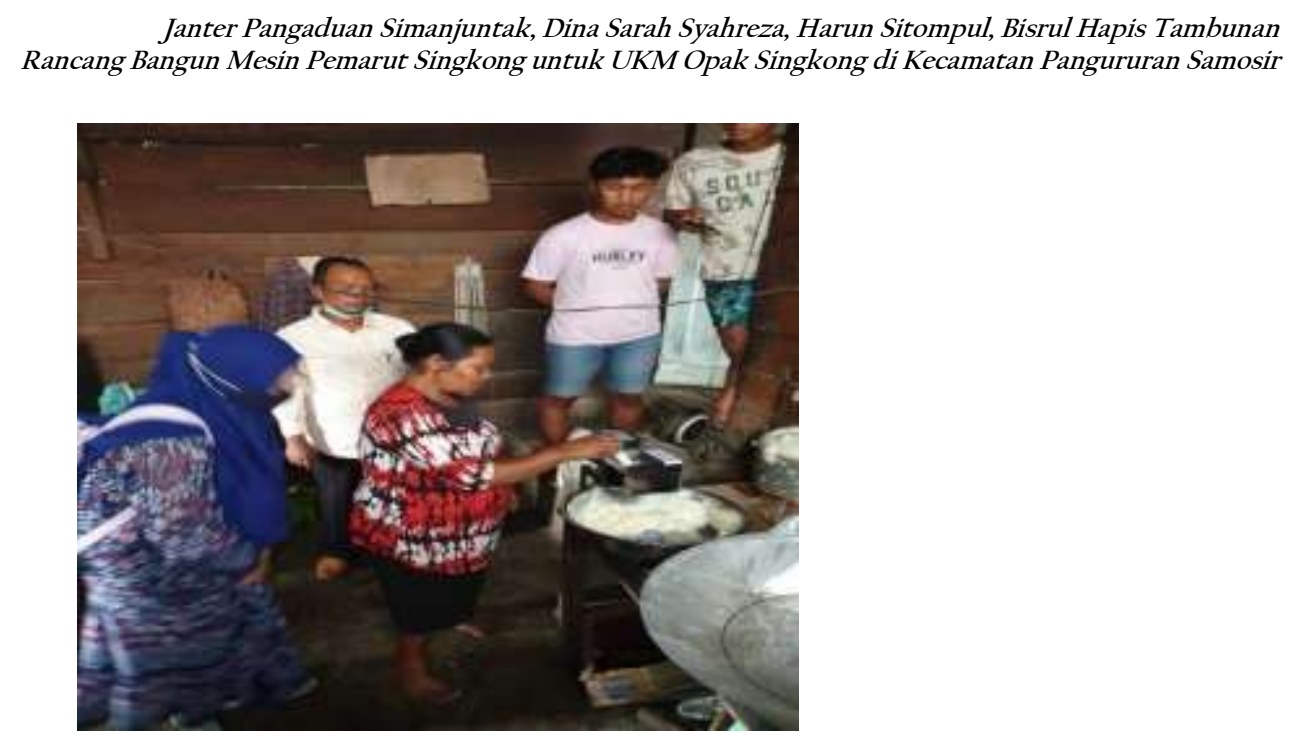

\section{Gambar 4. Pendampingan Cara penggunanaan dan perawatan Mesil pemarut}

\subsection{Penerapan teknologi tepat guna}

Pelatihan dan Penerapan teknologi tepat guna sangat berpengaruh signifikan terhadap keberdayaan UMKM (Andarwati, Subiyantoro, \& Subadyo, 2018),(Gede Suarjana, Gede Adiatmika, \& Bandem Adnyana, 2018). Solusi yang disepakati dari permasalahan dibidang produksi adalah perlunya diadakan mesin pemarut singkong yang bertujuan untuk meningkatkan kapasitas produksi. Untuk itu tim pengusul yang salah satunya merupakan pakar dalam bidang teknik mesin berdiskusi dengan mitra untuk mendapatkan desain serta konstruksi mesin pemarut singkong yang dimaksud oleh mitra. Proses produksi mesin pemarut singkong menggunakan kaidah-kaidāh yang sesuai untuk mesin pengolahan bahan baku makanan, diantaranya tidak mudah berkarat, didesain agar mudah dalam perawatan dan pengoperasiannya, hal ini sesuai dengan kriteria disain mesin Teknologi Tepat Guna, Sehingga mitra benar-benar memanfaatkan mesin tersebut secara maksimal.(Darmawa, Sudana, \& Aryana, 2017),(Subhan, Rodika, \& Kurniawan, 2018)

\subsection{Pendampingan}

Dalam penerapat Teknologi pada UMKM pendampingan dilakukan sebagai bentuk layanan yang diberikan ke mitra pelaku usaha secara intensif dan berkelanjutan untuk memastikan penggunaan dan perawatan mesin sesuai dengan SOP (Nursalim, Sampeallo, Wahid, \& Meok, 2021). Dalam hal ini pendampingan yag dilakukan tim adalah pengoperasian dan perawatan mesin. Hal ini sangat perlu dilakukan agar tidak terjadi kerusakan fatal pada mesin akibat kesalahan prosedur pengoperasian. Pendampingan perawatan di lakukan agar life time mesin panjang dan Mitra dapat merasakan manfaatnya dalam jangka waktu lama (Kriswanto \& Widodo, 2018; Kurniawan \& Subhan, 2021; Sutoyo \& Mojosongo, 2018).

\section{Hasil dan Pembahasan}

Hasil dan luaran yang di peroleh dalam pelaksanaan program adalah selama 6 bulan di Kelurahan Pasar Pangururan, Kecamatan Pangururan Kabupaten Samosir, antara lain:

\subsection{Mesin Parut Singkong}

Tim pengusul berhasil mendisain dan memproduksi 1 unit mesin parut khusus singkong yang penggunaanya lebih aman dan hasil perutan maksimal (tidak ada sisa singkong yang tidak terparut). Mesin ini dihibahkan kepada Mitra secara cuma-cuma. 


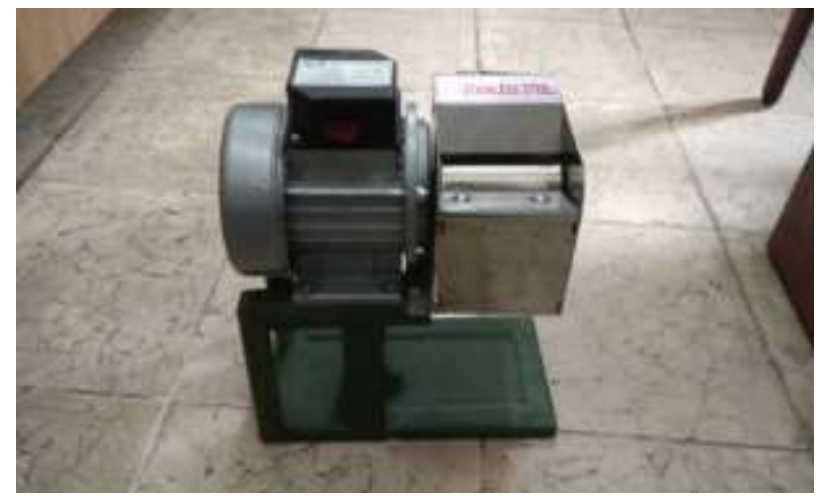

\section{Gambar 5. Mesin Parut Singkong yang di serahkan ke Mitra}

\subsection{Waktu pemarutan menjadi lebih cepat.}

Sebelum menggunakan mesin Pemarut singkong, untu memarut singkong seberat $30 \mathrm{~kg}$, dibutuhkan waktu rata-rata 50-60 menit, setelah menggunakan mesin parut singkong hanya butuh waktu 20-30 menit. Dalam pengamatan tim, Mitra lebih merasa aman dalam menggunakan mesin parut singkong. Hasil ini suai dengan beberapa prongram pengabdian yang sudah dilakukan oleh pengabdi lain di lokasi dan UMKN lainnya. (Firdaus, Habib, \& Sugiono, 2018; Hindratmo, Riyanto, \& Tajuddin, 2020; Trianasari, Pamuji, Prayogo, \& Rahayu, 2017).

\subsection{Seluruh singkong dapat terparut.}

Setelah menggunakan Mesin Parut singkong, tidak ada lagi sisa singkong yang tidak bisa di parut, karena singkong yang diparut tidak harus dipegang oleh operator.

\subsection{Publikasi di media cetak.}

Kegiatan ini juga di liput oleh media cetak koran Waspada edisi 23 September 2020

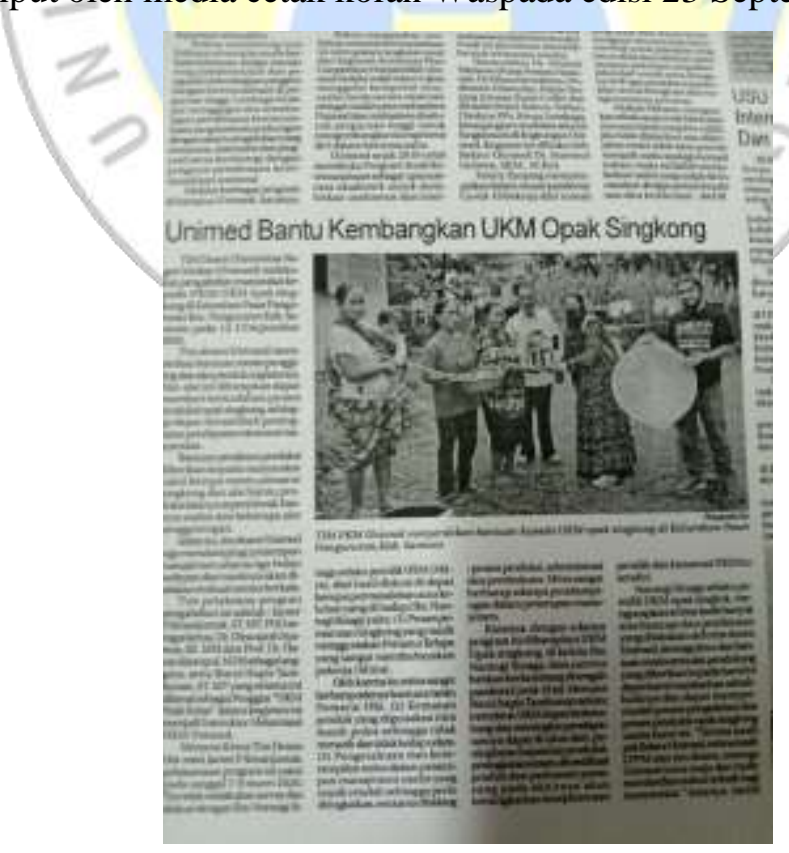

Gambar 6. Koran Waspada 23 Sep. 2020 


\subsection{Publikasi di Web Universitas.}

Kegiatan ini juga ditampilkan oleh pihak Humas di Website Universitas Negeri Medan karena dianggap positif dalam membantu UKM dalam penerapat IPTEK dan membangun Citra Universitas.

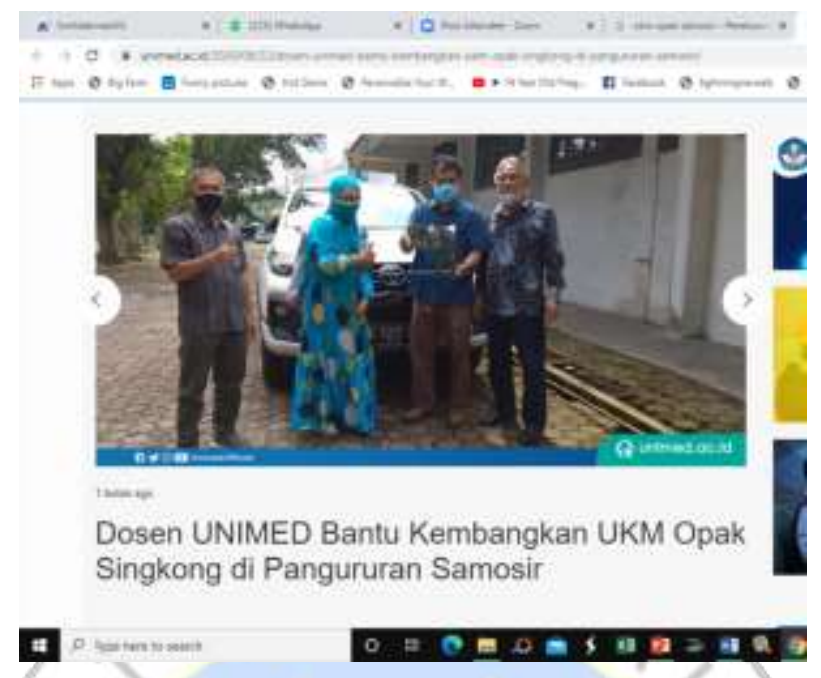

Gambar 7. Tampilan kegiatan di Web Universitas

\section{Kesimpulan}

Mesin Parut singkong yang di berikan dapat mengatasi permasalahan Mitra di bidang produksi, yakni efisiensi pemarutan meningkat dan keselamatan operator pemarut dapat terjaga.

\section{Daftar Pustaka}

Andarwati, M., Subiyantoro, E., \& Subadyo, A. T. (2018). Pengaruh pelatihan dan penerapan teknologi tepat guna (TTG) terhadap keberdayaan pengrajin batik tulis ramah lingkungan. Briliant: Jurnal Riset dan Konseptual, 3(3), 280-286.

Darmawa, I. P., Sudana, I. M., \& Aryana, I. W. (2017). Pemanfaatan Teknologi Tepat Guna Berupa Mesin Pencacah Pakan Ternak Kambing Di Desa Sepang Kabupaten Buleleng. Bhakti Persada Jurnal Aplikasi IPTEKS, 1(1), 81.

Deyulmar, B. A., Suroto, S., \& Wahyuni, I. (2018). Analisis Faktor-Faktor Yang Berhubungan dengan Kelelahan Kerja Pada Pekerja Pembuat Kerupuk Opak di Desa Ngadikerso, Kabupaten Semarang. Jurnal Kesehatan Masyarakat (e-Journal), 6(4), 278-285.

Firdaus, M., Habib, A., \& Sugiono, S. (2018). Peningkatan Kualitas dan Kapasitas Produksi Serta Pemasaran Produk UKM (Studi Kasus UKM Keripik Pisang dan Ketela di Trawas Mojokerto). Seminar Nasional Hasil Penelitian dan Pengabdian Masyarakat, 1(1).

Gede Suarjana, I. W., Gede Adiatmika, I. P., \& Bandem Adnyana, I. W. (2018). Redesain Alat Pemarut Kelapa Mengurangi Beban Fisiologis dan Meningkatkan Produktivitas Kerja pada Pekerja Industri Adonan (Luluh) Sate di Desa Kaba-kaba Kediri Tabanan. Jurnal Ergonomi Indonesia, 4(2), 39-52.

Hindratmo, A., Riyanto, O. A. W., \& Tajuddin, U. (2020). Penerapan Teknologi Tepat Guna dan Perbaikan Manajemen Produksi UMKM Krupuk Puli Sidoarjo. Prosiding Konferensi Nasional Pengabdian Kepada Masyarakat Dan Corporate Social Responsibility (PKM-CSR), 3, 129-135.

$$
\begin{array}{r}
\text { ABDI: Jurnal Pengabdian dan Pemberdayaan Masyarakat Vol. } 3 \text { No. } 2 \\
\text { E-ISSN: 2684-8570| ABDI } 2021 \\
\text { Copyright }{ }^{\odot} \text { 2021, By Author }
\end{array}
$$


Kriswanto, K., \& Widodo, R. D. (2018). Mesin Pengolah Minuman Kesehatan Instan Untuk Home Industry Healthy Desa Limbangan Kecamatan Limbangan Kabupaten Kendal. Rekayasa: Jurnal Penerapan Teknologi Dan Pembelajaran, 15(1), 17-24.

Kurniawan, Z., \& Subhan, M. (2021). Pengabdian Kepada Masyarakat Usaha Pangan Lokal Berbasis Tepung Ubi Di Tempilang Kabupaten Bangka Barat. Jurnal Pengabdian Masyarakat Polmanbabel, 1(01), 2128.

Mude, M. A. (2016). Perbandingan Metode SAW dan TOPSIS pada kasus UMKM. ILKOM Jurnal Ilmiah, $8(2), 76-81$.

Muktiadji, N., \& Hendrian, G. (2018). Pelatihan Motivasi Usaha Bagi UMKM Kota Bogor. Jurnal Abdimas, 2(1), 78-82.

Nursalim, N., Sampeallo, A. S., Wahid, A., \& Meok, N. J. (2021). Pendampingan dan Penerapan Teknologi Tepat Guna untuk Peningkatan Produktivitas Usaha Mebel Kota Kupang. Abdimas: Jurnal Pengabdian Masyarakat Universitas Merdeka Malang, 6(1), 82-89.

Rahmadani, L. S., et al. (2019). Inovasi serta Pelatihan Pengolahan Singkong sebagai Upaya Menumbuhkan Jiwa Kewirausahaan Masyarakat Dusun Sumber Desa Planjan Kecamatan Saptosari Kabupaten Gunung Kidul. Prosiding Konferensi Pengabdian Masyarakat, 1, 401-404.

Rijanto, A., \& Rahayuningsih, S. (2018). Peningkatan Kapasitas Produksi Melalui Penerapan Alih Teknologi Pada Usaha Mikro Keripik Singkong. J-ADIMAS (Jurnal Pengabdian Kepada Masyarakat), 6(1), 1-8.

Badan Pusat Statistik Kabupaten Samosir. (2018). Kecamatan Pangururan Dalam Angka 2017. Kabupaten Samosir: BPS Kabupaten Samosir

Subhan, M., Rodika, R., \& Kurniawan, Z. (2018). Rancang Bangun Mesin Mesin Pencetak Beras Analog Sebagai Pangan Lokal Daerah Bangka. Prosiding Semnastek.

Sutoyo, J. L., \& Mojosongo, S. (2020). Perbaikan Proses Produksi Jamu Instan Daun Salam (Syzigium polyantum) Kelompok Pawon Herbalku Boyolali. Dimas Budi: Jurnal Pengabdian kepada Masyarakat, 4(1), 20-25

Trianasari, E., Pamuji, D. R., Prayogo, G. S., \& Rahayu, N. S. (2017). Pemanfaatan Teknologi Tepat Guna Mesin Pengiris Tempe Untuk Meningkatkan Produktifitas UMKM Keripik Tempe di Desa Siliragung Kecamatan Siliragung. Addi, 10(1), 64-66.

Ummi, N., Irman, A., Ferdinant, P. F., \& Gunawan, A. (2018). Rancangan Pembuatan Mesin Giling Untuk Menghasilkan Bahan Baku Opak Singkong dengan Pendekatan Quality Function Deployment (QFD) dan Analitical Hierarchy Process (AHP). Prosiding Seminar Nasional Teknologi, Inovasi dan Aplikasi di Lingkungan Tropis, 1(1), 1-7. 